\title{
Mechanical Thrombectomy in Elderly Stroke Patients with Mild-to-Moderate Baseline Disability
}

\author{
Diana E. Slawski ${ }^{a} \quad$ Hisham Salahuddin ${ }^{b}$ Julie Shawver ${ }^{c}$ \\ Cynthia L. Kenmuir ${ }^{d} \quad$ Gretchen E. Tietjen $^{\mathrm{e}}$ Andrea Korsnack $^{\mathrm{e}}$ \\ Syed F. Zaidie Mouhammad A. Jumaa ${ }^{\mathrm{e}}$ \\ a University of Toledo College of Medicine and Life Sciences, Toledo, OH, USA; \\ buniversity of Texas Southwestern Medical Center, Dallas, TX, USA; 'ProMedica Toledo \\ Hospital, Toledo, OH, USA; dUniversity of Pittsburgh Medical Center, Pittsburgh, PA, USA; \\ e University of Toledo Medical Center, Toledo, OH, USA
}

\author{
Keywords \\ Stroke $\cdot$ Thrombectomy $\cdot$ Elderly $\cdot$ Disability $\cdot$ Outcomes
}

\begin{abstract}
Background: The number of elderly patients suffering from ischemic stroke is rising. Randomized trials of mechanical thrombectomy (MT) generally exclude patients over the age of 80 years with baseline disability. The aim of this study was to understand the efficacy and safety of MT in elderly patients, many of whom may have baseline impairment. Methods: Between January 2015 and April 2017, 96 patients $\geq 80$ years old who underwent MT for stroke were selected for a chart review. The data included baseline characteristics, time to treatment, the rate of revascularization, procedural complications, mortality, and 90-day good outcome defined as a modified Rankin Scale (mRS) score of 0-2 or return to baseline. Results: Of the 96 patients, 50 had mild baseline disability (mRS score $0-1$ ) and 46 had moderate disability (mRS score 2-4). Recanalization was achieved in $84 \%$ of the patients, and the rate of symptomatic hemorrhage was $6 \%$. At 90 days, $34 \%$ of the patients had a good outcome. There were no significant differences in good outcome between those with mild and those with moderate baseline disability ( 43 vs. $24 \%, p=0.08$ ), between those aged $\leq 85$ and those aged $>85$ years $(40.8$ vs. $26.1 \%, p=0.19)$, and between those treated within and those treated beyond 8 h (39 vs. $20 \%, p=0.1$ ). The mortality rate was $38.5 \%$ at 90 days. The Alberta Stroke Program Early CT Score (ASPECTS) and the National Institutes of Health Stroke Scale (NIHSS) predicted good outcome regardless of baseline disability $(p<0.001$ and $p=0.009$, respectively). Con-
\end{abstract}

Mouhammad A. Jumaa, MD

University of Toledo Medical Center

3000 Arlington Avenue

Toledo, OH 43614 (USA)

E-Mail mouhammad.jumaa@utoledo.edu 
clusion: Advanced age, baseline disability, and delayed treatment are associated with suboptimal outcomes after MT. However, redefining good outcome to include return to baseline functioning demonstrates that one-third of this patient population benefits from MT, suggesting the real-life utility of this treatment.

(C) 2018 S. Karger AG, Basel

\section{Introduction}

Acute ischemic stroke is a major cause of disability in the USA. About $30 \%$ of all strokes occur in patients over the age of 80 years, with $17 \%$ occurring in patients over 85 years [1]. It is anticipated that the incidence of stroke will more than double by 2050 , with the largest proportion of these incident cases occurring among patients 75 years and older and minorities [2].

A recentanalysis of the Get with the Guidelines-Stroke study population showed improved adherence to treatment recommendations among elderly stroke patients [3]. Despite closing the gap in age-related differences in care, elderly stroke patients continue to have poor outcomes with higher mortality and significant disability at discharge compared to younger patients $[3,4]$. Known predictors of poor outcome in elderly patients include comorbidities and risk factors such as hypertension and atrial fibrillation, an age $\geq 80$ years, baseline disability, an initial National Institutes of Health Stroke Scale (NIHSS) score $\geq 7$, and medical complications during acute hospitalization [3-6]. Traditional medical therapy has consequently yielded suboptimal results in this patient population, with a reported mortality of $45 \%$ [7].

Current data regarding treatment with mechanical thrombectomy (MT) in elderly patients are limited to those with mild baseline disability. Recent randomized trials have primarily enrolled patients between the age of 18 and 80 years with no significant baseline disability [8-10], although some trials did include octogenarians [9, 11-13]. Under these conditions, the results showed that MT not only was safe but also produced the strongest treatment effect in patients $\geq 80$ years old $[7,14]$. Despite these encouraging results, there is a lack of data describing real-life outcomes in both elderly patients with mild and those with moderate baseline disability. As many as $33 \%$ of octogenarians presenting with ischemic stroke are not independent at baseline [15], and as the aging population grows, the number of elderly patients requiring treatment will increase. Therefore, the potential utility of MT in this group is of interest.

The purpose of this study is to evaluate the safety and efficacy of MT for ischemic stroke in patients $\geq 80$ years old with baseline modified Rankin Scale (mRS) scores of $0-4$. The results of this cohort were compared to those reported in randomized trials in order to understand the benefits of MT in the context of real-life treatment of elderly stroke patients with variable baseline disability.

\section{Methods}

Patients and Variables

This study identified consecutive patients in a prospectively collected MT database of anterior circulation acute ischemic stroke cases between January 2015 and April 2017. With institutional review board approval, we retrospectively collected data on all patients aged $\geq 80$ years who had received MT during this time at two tertiary care centers in Ohio, USA. The baseline demographics, procedural variables, and postprocedural outcomes were recorded. Symptomatic intracranial hemorrhage (sICH) was defined as an increase in NIHSS score of $\geq 4$ points with evidence of hemorrhagic conversion on CT. Pre-stroke mRS scores 
were obtained upon initial presentation, and scores of $0-1$ were considered "mild disability," while scores of 2-4 were considered "moderate disability." Good recanalization was defined as a TICI (Thrombolysis in Cerebral Infarction) grade $\geq 2 \mathrm{~b}$, and good outcome was defined as a 90 -day mRS score $\leq 2$ or return to baseline of function. NIHSS and mRS scores were assessed by certified nurse practitioners or stroke neurologists, and 90-day outcomes were assessed during clinic visits or by phone interview.

Elderly patients who presented with anterior circulation acute ischemic stroke and who had baseline mRS scores of 0-4 were taken for thrombectomy in accordance with family or guardian consent. Patients with severe disability (mRS score 5), advanced dementia, and comfort care measures in place were not treated. Patients were selected if the Alberta Stroke Program Early CT Score (ASPECTS) on noncontrast CT was $>6$. CTA was performed to demonstrate evidence of vessel occlusion in all cases unless noncontrast CT showed a hyperdense vessel sign. Thrombectomy beyond $8 \mathrm{~h}$ from symptom onset was undertaken if perfusion imaging (CT perfusion) showed a small core and large perfusion deficit. Patients transferred from outside facilities were managed according to a drip-and-ship protocol with imaging at our institutions upon arrival. Post-thrombectomy care included monitoring in the neurointensive care unit and evaluation for development of intracerebral hemorrhage on CT at $24 \mathrm{~h}$.

Endovascular Technique

The patients underwent MT with second-generation stent retrievers (Trevo or Solitaire) and/or aspiration with a Penumbra catheter at the discretion of the neurointerventionalist. Conscious sedation was preferred to general anesthesia; however, in cases of noncompliance or respiratory distress, patients were intubated and maintained under general anesthesia.

\section{Statistical Analysis}

Data were compiled in an Excel file and exported to a statistical analysis software (R: A Language and Environment for Statistical Computing; EZR version 1.32). Continuous variables were compared using the Student $t$ test with the Welch test or the Mann-Whitney test, and categorical data with the Fisher exact test when appropriate. Patients lost to follow-up were excluded from the final analysis. A multivariate logistic regression analysis was performed to evaluate for clinically significant predictors of favorable outcome. A $p$ value of $<0.05$ was considered statistically significant.

\section{Results}

We analyzed 96 patients over a 27 -month period at one primary stroke center and one comprehensive stroke center. For the primary analysis, the patients were divided into two groups according to their baseline mRS score: $0-1$ indicating mild disability $(n=50)$ and 2-4 indicating moderate disability $(n=46)$. There were 44 patients with a baseline $\mathrm{mRS}$ score of 0,6 patients with a score of 1,12 patients with a score of 2,18 patients with a score of 3 , and 16 patients with a score of 4 . One patient in the mild disability group was lost to follow-up. The baseline characteristics, comorbidities, and outcomes are summarized in Table 1.

At baseline, the moderate disability group differed significantly in that the patients were older (mean age 86.7 vs. 85 years, $p=0.017$ ) and there were more female patients (76.1 vs. $50 \%, p=0.01$ ). Compared to the mild disability group, in the moderate disability group significantly more patients were diagnosed with dementia (28.3 vs. $4 \%, p=0.001)$ and anxiety or depression ( 37 vs. $8 \%, p<0.001$ ). The successful recanalization rate in the overall cohort was $84.4 \%$, with no differences between the patients with mild and those with moderate baseline disability ( 84.0 vs. $84.8 \%, p=1.0$ ). The overall rate of hemorrhagic transformation was $37.5 \%$, with $6.3 \%$ of the patients experiencing sICH. Arterial dissection occurred in $4.2 \%$ and subarachnoid hemorrhage in $5.2 \%$ of the patients in the overall cohort.

Good outcome at 90 days was attained in $33.7 \%$ of the patients. Forty-three percent of the patients with mild baseline impairment achieved a good outcome, compared to $23.9 \%$ of those with moderate baseline disability. However, there was no significant difference between the groups $(p=0.08)$. The overall mortality rate was $38.5 \%$, with significantly higher mortality 
Table 1. Baseline characteristics, treatment metrics, and outcomes for the overall cohort of elderly patients and subgroups of those with an mRS score of $0-1$ and those with an mRS score of 2-4 at baseline

\begin{tabular}{|c|c|c|c|c|}
\hline & $\begin{array}{l}\text { Total } \\
(n=96)\end{array}$ & $\begin{array}{l}\text { mRS score } 0-1 \\
(n=50)\end{array}$ & $\begin{array}{l}\text { mRS score } 2-4 \\
(n=46)\end{array}$ & $p$ value \\
\hline \multicolumn{5}{|l|}{ Baseline characteristics } \\
\hline \multicolumn{5}{|l|}{ Age, years } \\
\hline Mean \pm SD & $85.8 \pm 3.67$ & $85.0 \pm 3.0$ & $86.7 \pm 4.1$ & 0.017 \\
\hline Range & 80-97 & 80-94 & $80-97$ & \\
\hline Female & $60(62.5)$ & $25(50)$ & $35(76.1)$ & 0.011 \\
\hline Atrial fibrillation & $61(63.5)$ & $31(62)$ & $30(65.2)$ & 0.833 \\
\hline Hypertension & $84(87.5)$ & $43(86)$ & $41(89.1)$ & 0.762 \\
\hline Hyperlipidemia & $58(60.4)$ & $29(58)$ & $29(63)$ & 0.679 \\
\hline LDL, mg/dL & $77.3 \pm 31.2$ & $76.0 \pm 20.2$ & $78.7 \pm 32.6$ & 0.957 \\
\hline Diabetes mellitus & $20(20.8)$ & $10(20)$ & $10(21.7)$ & 1.0 \\
\hline $\mathrm{HbA}_{1 \mathrm{c}}, \%$ & $6.0 \pm 0.74$ & $5.84 \pm 0.59$ & $6.15 \pm 0.86$ & 0.051 \\
\hline Smoking & $4(4.2)$ & $3(6)$ & $1(2.2)$ & 0.618 \\
\hline Coronary artery disease & $36(37.5)$ & $19(38)$ & $17(37)$ & 1.0 \\
\hline Age $\leq 85$ years & $50(52)$ & $30(60)$ & $20(43.5)$ & 0.152 \\
\hline \multicolumn{5}{|l|}{ Additional comorbidities } \\
\hline Dementia & $15(15.6)$ & $2(4)$ & $13(28.3)$ & 0.001 \\
\hline Congestive heart failure & $21(21.9)$ & $7(14)$ & $14(30.4)$ & 0.082 \\
\hline COPD & $16(16.7)$ & $8(16)$ & $8(17.4)$ & 1.0 \\
\hline Anxiety/depression & $21(21.9)$ & $4(8)$ & $17(37)$ & $<0.001$ \\
\hline Trauma/recent surgery & $6(6.3)$ & $3(6)$ & $3(6.5)$ & 1.0 \\
\hline History of stroke & $10(10.4)$ & $3(6)$ & $7(15.2)$ & 0.187 \\
\hline Chronic kidney disease stage 5 & $2(2.1)$ & $1(2)$ & $1(2.2)$ & 1.0 \\
\hline Selection scan $(14,1 \mathrm{NA})$ & $(n=95)$ & $(n=49)$ & & \\
\hline $\mathrm{CT}$ & $42(44.2)$ & $25(51)$ & 17 (37) & 0.424 \\
\hline CTA & $36(37.9)$ & $17(34.7)$ & $19(41.3)$ & \\
\hline CT perfusion & $16(16.8)$ & $7(14.3)$ & $9(19.6)$ & \\
\hline MRI & $1(1.1)$ & $0(0)$ & $1(2.2)$ & \\
\hline \multicolumn{5}{|l|}{ Stroke characteristics } \\
\hline Admission NIHSS score & $18(14.5-23)$ & $17.5(13.25-21.75)$ & $19(15-24)$ & 0.081 \\
\hline ASPECTS & $8(8-9)$ & $8(8-9)$ & $8.5(8-9)$ & 0.969 \\
\hline Left sided & $54(56.25)$ & $31(62)$ & $23(50)$ & 0.304 \\
\hline IV tPA & $44(45.8)$ & $24(48)$ & $20(43.5)$ & 0.686 \\
\hline ICA - T & $25(26.0)$ & $9(18)$ & $16(34.8)$ & 0.068 \\
\hline Proximal ICA & $7(7.3)$ & $3(6)$ & $4(8.7)$ & 0.707 \\
\hline Tandem & $7(7.3)$ & $2(4)$ & $5(20.9)$ & 0.254 \\
\hline M1 & $54(56.25)$ & $31(62)$ & $23(50)$ & 0.304 \\
\hline M2 & $21(21.9)$ & $12(24)$ & $9(19.6)$ & 0.630 \\
\hline M3 & $3(3.1)$ & $0(0)$ & $3(6.5)$ & 0.106 \\
\hline \multicolumn{5}{|l|}{ Treatment metrics } \\
\hline LKN to arrival, min & $158(77-356)$ & $160(74-364)$ & $151(88-317)$ & 1.0 \\
\hline Door to groin puncture, min & $58(35-87)$ & $56(34.5-87)$ & $63(40-85.5)$ & 0.729 \\
\hline LKN to groin puncture, min & $206(120-412)$ & $214(120-420)$ & $202(120-360)$ & 0.844 \\
\hline Procedure time, min & $28(20-43)$ & $27(20-48)$ & $30(20-40)$ & 0.794 \\
\hline 8-h onset to groin puncture, $\min$ & $71(74)$ & $39(78)$ & $32(69.6)$ & 0.364 \\
\hline \multicolumn{5}{|l|}{ LKN to recanalization } \\
\hline (TICI $2 \mathrm{~b}$ or 3 ), $\min$ & $254(166-436)$ & $252(161-452)$ & 255 (199-337) & 0.974 \\
\hline Only aspiration & $33(34.4)$ & $14(28)$ & $19(41.3)$ & 0.201 \\
\hline Stent retriever & $59(61.5)$ & $34(68)$ & $25(54.3)$ & 0.210 \\
\hline Successful recanalization & $81(84.4)$ & $42(84)$ & $39(84.8)$ & 1.0 \\
\hline
\end{tabular}


Table 1 (continued)

\begin{tabular}{|c|c|c|c|c|}
\hline & $\begin{array}{l}\text { Total } \\
(n=96)\end{array}$ & $\begin{array}{l}\text { mRS score } 0-1 \\
(n=50)\end{array}$ & $\begin{array}{l}\text { mRS score } 2-4 \\
(n=46)\end{array}$ & $p$ value \\
\hline \multicolumn{5}{|l|}{ Clinical outcomes } \\
\hline Good outcome & $32(33.7)^{1}$ & $21(42.9)^{2}$ & $11(23.9)$ & 0.082 \\
\hline Death & $37(38.5)$ & $13(26)$ & $24(52.2)$ & 0.012 \\
\hline \multicolumn{5}{|l|}{ Change from baseline mRS score } \\
\hline Mean \pm SD & $2.4 \pm 2.0$ & $3.0 \pm 2.3$ & $1.8 \pm 1.3$ & 0.018 \\
\hline Median (IQR) & $2(1-4)$ & $3(1-6)$ & $2(1-3)$ & \\
\hline \multicolumn{5}{|l|}{ Discharge NIHSS score } \\
\hline Median (IQR) & $7(3-12)$ & $6(2-9)$ & $10(5-14.5)$ & 0.021 \\
\hline \multicolumn{5}{|l|}{ Dramatic improvement in } \\
\hline NIHSS score & $58(60.4)$ & $34(68)$ & $24(52.2)$ & 0.145 \\
\hline Improvement in NIHSS score & $10(5-14)$ & $11(5-14.5)$ & $9.5(5-13.25)$ & 0.576 \\
\hline \multicolumn{5}{|l|}{ Hemorrhagic complications } \\
\hline Hemorrhagic transformation & $28(29.2)$ & $17(34)$ & $11(23.9)$ & 0.369 \\
\hline Parenchymal hematoma & $8(8.3)$ & $4(8)$ & 4 (8.7) & 1.0 \\
\hline sICH & $6(6.25)$ & $2(4)$ & $4(8.7)$ & 0.422 \\
\hline \multicolumn{5}{|l|}{ Procedural complications } \\
\hline Arterial dissection & $4(4.2)$ & $3(6)$ & $1(2.2)$ & 0.618 \\
\hline Subarachnoid hemorrhage & $5(5.2)$ & $1(2)$ & $4(8.7)$ & 0.191 \\
\hline Any in-hospital complication & $29(30.2)$ & $14(28)$ & $15(32.6)$ & 0.662 \\
\hline Tracheostomy & $3(3.1)$ & $1(2)$ & $2(4.3)$ & 0.606 \\
\hline PEG tube & $13(13.5)$ & $3(6)$ & $10(21.7)$ & 0.035 \\
\hline \multicolumn{5}{|l|}{ Discharge disposition } \\
\hline Home & 7 (7.29) & $4(8)$ & $3(6.5)$ & $<0.001$ \\
\hline Inpatient rehabilitation & $32(33.3)$ & $29(58)$ & $3(6.5)$ & \\
\hline Skilled nursing facility & $37(38.5)$ & $10(20)$ & $27(58.7)$ & \\
\hline Long-term acute care & $3(3.1)$ & $0(0)$ & $3(6.5)$ & \\
\hline Hospice & $11(11.5)$ & $7(14)$ & $4(8.7)$ & \\
\hline In-hospital mortality & $5(6.3)$ & $0(0)$ & $6(13)$ & \\
\hline
\end{tabular}

Values are presented as $n(\%)$, mean $\pm \mathrm{SD}$, or median (IQR). Under "additional comorbidities," the category for recent trauma/surgery includes falls, bowel surgery, subdural hematoma, and hip replacement. In-hospital medical complications include aspiration pneumonia, respiratory failure requiring ventilatory support, urinary tract infection, acute delirium, sepsis, PEG tube displacement, deep vein thrombosis, and cardiac arrest. mRS, modified Rankin Scale; COPD, chronic obstructive pulmonary disease; tPA, tissue plasminogen activator; ICA, internal carotid artery; LKN, last known normal; sICH, symptomatic intracranial hemorrhage. ${ }^{1} n=95 .{ }^{2} n=49$.

among the patients with moderate as compared to those with mild baseline disability $(52.2$ vs. $26 \%, p=0.01$ ).

The rate of in-hospital complications such as pneumonia or urinary tract infection was $30.2 \%$ in the overall cohort, with no significant difference between the groups. PEG tubes were more frequently placed in patients with moderate baseline disability $(21.7 \%)$ as compared to those with mild disability $(6 \%, p=0.035)$.

The most common location for discharge in this cohort was a skilled nursing facility $(38.5 \%)$ (Table 1). The discharge disposition was significantly different between the groups $(p<0.001)$. Patients in the mild baseline disability group were more frequently discharged home and to inpatient rehabilitation when compared to the moderate disability group (8vs. $6.5 \%$ and 58 vs. $6.5 \%$, respectively). Those with moderate disability more often went to skilled nursing (58.7\%) or long-term acute care (6.5\%). In-hospital mortality was significantly higher among those with moderate baseline disability (13 vs. $0 \%, p<0.001$ ). 


\section{Secondary Analysis: Comparison of Outcomes by Age}

An additional analysis was performed comparing outcomes stratified by patient age, with patients $\leq 85$ years old $(n=50)$ compared to those $>85$ years old $(n=46)$ (online suppl. Table I; for all online suppl. material, see www.karger.com/doi/10.1159/000487333). One patient in the younger group was lost to follow-up. The groups were not significantly different at baseline and had similar treatment metrics. The successful revascularization rate was not significantly different between the groups ( 90 vs. $78.3 \%, p=0.2$ ). There was no significant difference between patients $\leq 85$ years old and those $>85$ years old in the rate of good outcome ( 40.8 vs. $26.1 \%, p=0.2$ ) or mortality ( 34 vs. $43.5 \%, p=0.4$ ). In a pattern similar to that of the first subgroup analysis by mRS score, the discharge disposition was significantly different ( $p=0.002$ ) between the age subgroups, with the patients $>85$ years old being less frequently discharged home or to inpatient rehabilitation than the younger patients.

\section{Secondary Analysis: Comparison of Outcomes by Time to Treatment}

We assessed for differences in outcome between the patients treated within $8 \mathrm{~h}$ of symptom onset $(n=71)$ and those treated beyond $8 \mathrm{~h}$ from symptom onset $(n=25)$ (online suppl. Table II). One patient treated within $8 \mathrm{~h}$ was lost to follow-up. There was no difference in the rate of good outcome at 90 days between the two groups $(38.6 \%$ within $8 \mathrm{~h}$ vs. $20 \%$ beyond $8 \mathrm{~h}, p=0.14$ ). The mortality rate among those treated beyond $8 \mathrm{~h}$ was not significantly

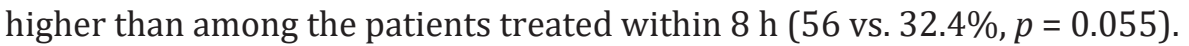

We performed a univariate analysis of the baseline characteristics, comorbidities, time metrics, device used, recanalization grades, and complications and found that NIHSS score $(p=0.009)$ and ASPECTS $(p<0.001)$ were the only significant predictors of good outcome. Using these variables in our prediction model, we found that ASPECTS (OR 4.49, 95\% CI 1.99$10.10, p<0.001$ ) and NIHSS score (OR 0.897, 95\% CI 0.818-0.984, $p=0.02$ ) were adequate predictors of good outcome.

\section{Discussion}

In this study, we examined outcomes in patients $\geq 80$ years old who underwent MT for ischemic stroke. This "real-life," comprehensive cohort of elderly patients included those who underwent MT despite a mild-to-moderate degree of baseline disability. Our findings demonstrated that good outcomes were less common but still attainable in patients who were very elderly, had moderate baseline disability, or received delayed treatment. The mortality rates were significantly higher among the patients with moderate disability.

The recent HERMES analysis [7] and STRATIS registry [16] included elderly patients aged $\geq 80$ years without baseline disability and reported good outcomes (mRS score $0-2$ ) in 29.8 and $43.2 \%$ of the patients, respectively (Table 2). Similarly, our rate of mRS scores of $0-2$ among patients without baseline disability was $40.8 \%$, thus supporting the findings of HERMES and STRATIS that patients aged $\geq 80$ years achieve respectable rates of functional recovery when their premorbid disability is minimal.

There is an overall lack of data describing outcomes in patients who are not independent at baseline. Our results show that $23.9 \%$ of the patients with moderate disability could achieve a good outcome when the definition was expanded to include return to premorbid functional status.

Our 90-day mortality rate of $26 \%$ among elderly patients with premorbid independence aligns well with the data in HERMES (28\%) and STRATIS (27.5\%). Our overall mortality rate increased to $38.5 \%$ after the inclusion of patients with moderate baseline disability. 


\section{Interventional Neurology}

Table 2. Comparison of outcomes in elderly patients treated with mechanical thrombectomy

\begin{tabular}{|c|c|c|c|c|c|c|c|}
\hline Study [Ref.], year & $\begin{array}{l}\text { MT patients } \\
\geq 80 \text { years, } n\end{array}$ & $\mathrm{tPA}$ & $\begin{array}{l}\text { Baseline mRS } \\
\text { score }\end{array}$ & $\begin{array}{l}\text { Good } \\
\text { recanalization }\end{array}$ & $\begin{array}{l}\text { Rate of } \\
\text { sICH }\end{array}$ & $\begin{array}{l}\text { Good functional } \\
\text { outcome (mRS score } \\
\leq 2 \text { at } 90 \text { days) }\end{array}$ & $\begin{array}{l}\text { Mortality } \\
\text { at } 90 \text { days }\end{array}$ \\
\hline $\begin{array}{l}\text { Slawski } \\
\text { [this study], } \\
2018\end{array}$ & 96 & $45.8 \%$ & $\begin{array}{l}0: 44 \text { patients } \\
\text { 1: } 6 \text { patients } \\
\text { 2:12 patients } \\
\text { 3:18 patients } \\
\text { 4: } 16 \text { patients }\end{array}$ & $81 \%$ & $6 \%$ & $33.7 \%{ }^{1}$ & $38.5 \%$ \\
\hline $\begin{array}{l}\text { DAWN [19], } \\
2017\end{array}$ & 25 & ND & $\leq 1$ & ND & ND & $32 \%$ & $44 \% \%^{4}$ \\
\hline $\begin{array}{l}\text { STRATIS [16], } \\
2017\end{array}$ & 233 & $57 \%$ & $\leq 1$ & $86.6 \%$ & ND & $43.2 \%$ & $27.5 \%$ \\
\hline $\begin{array}{l}\text { HERMES [7], } \\
2016\end{array}$ & 198 & ND & $\leq 1^{2}$ & ND & ND & $29.8 \%$ & $28 \%$ \\
\hline $\begin{array}{l}\text { SEER [14], } \\
2016\end{array}$ & 74 & ND & $\leq 1$ & ND & ND & $38 \%$ & $20 \%$ \\
\hline $\begin{array}{l}\text { Son [21], } \\
2017\end{array}$ & 34 & $32.4 \%$ & $\leq 2$ & $82.4 \%$ & $5.9 \%$ & $44.1 \%$ & $2.9 \%$ \\
\hline $\begin{array}{l}\text { Azkune Calle [23], } \\
2017\end{array}$ & 31 & $25.8 \%$ & $\leq 2$ & $93.6 \%$ & $16.1 \%$ & $51.6 \%$ & $19.4 \%$ \\
\hline $\begin{array}{l}\text { Broussalis [22], } \\
2016\end{array}$ & 28 & $50 \%$ & $\leq 2$ & $68 \%$ & $18 \%$ & $31 \%$ & $19 \%$ \\
\hline $\begin{array}{l}\text { Lima [25], } \\
2016\end{array}$ & 111 & $46 \%$ & $\begin{array}{l}\text { 0-2: } 87 \text { patients } \\
\text { 3: } 14 \text { patients } \\
\text { ND: } 10 \text { patients }\end{array}$ & $80 \%$ & $7 \%$ & $29 \%$ & $41 \%$ \\
\hline $\begin{array}{l}\text { Parrilla [6], } \\
2015\end{array}$ & 34 & $32.4 \%$ & ND & $88.2 \%$ & $5.9 \%$ & $13.8 \%$ & $41.4 \%{ }^{3}$ \\
\hline $\begin{array}{l}\text { Hwang [27], } \\
2015\end{array}$ & 56 & $62.5 \%$ & $\leq 2$ & $82.1 \%$ & $10.7 \%$ & $35.7 \%$ & $14.3 \%$ \\
\hline $\begin{array}{l}\text { To [26], } \\
2015\end{array}$ & 18 & $16 \%$ & ND & $66 \%$ & $11 \%$ & $27.7 \%$ & $44.4 \%$ \\
\hline
\end{tabular}

MT, mechanical thrombectomy; tPA, tissue plasminogen activator; mRS, modified Rankin Scale; sICH, symptomatic intracranial hemorrhage; ND, no data available. ${ }^{1}$ Includes an mRS score of $0-2$ or return to baseline functioning. ${ }^{2}$ With 10 patients from MR CLEAN with a score $>2 .{ }^{3}$ Timing not specified. ${ }^{4}$ Includes mRS scores of 5 and 6.

It is evident that older patients with premorbid functional impairment have worse outcomes than those who are independent at baseline. Although the mechanisms underlying the connection of premorbid functional impairment and worse outcome remain unclear, frailty, a known predictor of poor outcome in stroke patients [17], may be an important factor to address in poststroke care.

In our study, the ASPECTS was a predictor of good outcome for the entire cohort. A study conducted by Danière et al. [18] found that the predictive value of the ASPECTS varied by age subgroup. The authors suggested that elderly patients are more likely to benefit from MT when the initial ASPECTS is higher and the ischemic core is small. Elderly patients are far less 
likely to achieve good outcomes when the core infarct size is large, though younger patients with a similar lesion severity are still able to experience good recovery [18]. Consequently, imaging may be a more selective tool than age or initial functional status when deciding on a treatment. Additionally, in our multivariate analysis there was no specific baseline comorbidity that predicted good outcome.

Elderly patients treated within $8 \mathrm{~h}$ tended to have better outcomes, though patients outside of this time window still benefitted. The recently completed DAWN study [19] showed that MT performed up to $24 \mathrm{~h}$ after symptom onset decreased disability; thus, treatment beyond $8 \mathrm{~h}$ is a reasonable pursuit. A significant drawback is the high mortality rate seen among elderly patients treated beyond $8 \mathrm{~h}$.

Revascularization is a key factor in predicting good outcome [20]. Elderly patients in our study and in others (Table 2) achieved good rates of recanalization despite the challenges of increasing atherosclerotic burden and vessel tortuosity with age [21-26]. However, many elderly patients still do not achieve good outcomes despite successful revascularization. The reported rate of futile recanalization among elderly patients has been $45-54 \%[23,27]$, and in our study it was $50.5 \%$. This is likely multifactorial, and possibly related to decreased neuronal plasticity with age and to diminished capacity to recruit the collateral circulation, with subsequently larger infarct volumes $[18,28,29]$.

Procedural complications merit careful attention due to the heightened risk of mortality in this vulnerable population. In our study, the rate of sICH overall was about $6 \%$. This, along with data regarding vessel dissection and subarachnoid hemorrhage, aligns well with data on other cohorts of elderly patients undergoing MT $[22,23]$ (Table 2). The average rate of sICH in HERMES was slightly less at $4.4 \%$, though it is still reasonable to conclude that elderly patients are not at increased risk of procedural complications. The rate of asymptomatic hemorrhagic transformation in our study was high, which, however, may be attributed to the generous rate of IV tissue plasminogen activator administration among our elderly patients. Of the $46 \%$ who received tissue plasminogen activator, $34 \%$ experienced hemorrhagic transformation.

With a waning life expectancy and increased risk of medical complications, it is reasonable to question the value of invasive treatments in elderly patients. The quality-adjusted life year (QALY) is a metric used for understanding treatment benefits. Steen Carlsson et al. [30] reported that MT produces QALY gains across all age groups, though the gains diminish with increasing age. In the context of disabling conditions like stroke, it may be argued that even small QALY gains may have a substantial impact, particularly at the end of life. A recent analysis based on findings from MR CLEAN concluded that MT is a cost-effective therapy even when including patients with disabling outcomes [31]. This suggests that the overall shift towards reduced disability compensates for any increased costs for patients with poorer outcomes.

In this study we created a broader definition of good outcome to demonstrate that patients with moderate-to-severe disability can benefit from MT with return to baseline functioning. The traditional definition of good outcome was useful in demonstrating the initial safety and efficacy of MT devices. However, when considering real-world applicability, good outcome can reasonably be expanded to include return to baseline functioning.

This study was limited by its retrospective design, and does not account for outcomes in elderly patients who were treated with conservative therapy only. Due to the nonrandomized nature of this study, there may have been a bias in patient selection for those with less severe presentations. Extensive information on baseline disability, such as the Barthel index and in-depth cognitive testing, was not available and was not part of the selection process. Information regarding the extent of dementia was based on family input, though mild dementia is frequently underdiagnosed and families often understate the extent of cognitive capacity in 
acute triage. Lastly, the sample size may have been too small to detect significant differences between groups.

At present, MT in the very elderly has demonstrated benefits when used selectively in those with mild baseline disability. Although good outcomes diminish with increasing age, premorbid disability, and delayed treatment time, the potential for reduced disability at low rates of procedural complications makes MT a reasonable therapy for stroke patients who are very elderly or may have baseline disability. Future randomized studies are necessary to elucidate whether the benefits of MT persist in those with some degree of disability, and whether the superiority of MT over standard medical therapy remains consistent in this population.

\section{Statement of Ethics}

This study was approved by the University of Toledo Institutional Review Board. Informed consent for human subjects was waived due to the minimal risk of loss of confidentiality.

\section{Disclosure Statement}

The authors have no conflicts of interest to disclose.

\section{Author Contributions}

D.E. Slawski contributed to the study design, data acquisition, and data interpretation; participated in drafting the manuscript; approved the final version; and agreed to be accountable for the quality and accuracy of this work.

H. Salahuddin contributed to the study design, data analysis, and data interpretation; participated in critically revising the manuscript; approved the final version; and agreed to be accountable for the quality and accuracy of this work.

J. Shawver and A. Korsnack contributed to data acquisition; participated in critically revising the manuscript; approved the final version; and agreed to be accountable for the quality and accuracy of this work.

C.L. Kenmuir, G.E. Tietjen, and S.F. Zaidi contributed to data interpretation; participated in critically revising the manuscript; approved the final version; and agreed to be accountable for the quality and accuracy of this work.

M.A. Jumaa contributed to the study conception and design, data analysis, and data interpretation; participated in drafting the manuscript and critical revisions; approved the final version; and agreed to be accountable for the quality and accuracy of this work.

\section{References}

1 Russo T, Felzani G, Marini C: Stroke in the very old: a systematic review of studies on incidence, outcome, and resource use. J Aging Res 2011;2011:108785.

2 Mozaffarian D, Benjamin EJ, Go AS, Arnett DK, Blaha MJ, Cushman M, et al: Heart disease and stroke statistics - 2015 update: a report from the American Heart Association. Circulation 2015;131:e29-e322.

3 Fonarow GC, Reeves MJ, Zhao X, Olson DM, Smith EE, Saver JL, et al: Age-related differences in characteristics, performance measures, treatment trends, and outcomes in patients with ischemic stroke. Circulation 2010; 121:879-891.

4 Forti P, Maioli F, Procaccianti G, Nativio V, Lega MV, Coveri M, et al: Independent predictors of ischemic stroke in the elderly: prospective data from a stroke unit. Neurology 2013;80:29-38.

5 Denti L, Scoditti U, Tonelli C, Saccavini M, Caminiti C, Valcavi R, et al: The poor outcome of ischemic stroke in very old people: a cohort study of its determinants. J Am Geriatr Soc 2010;58:12-17.

6 Parrilla G, Carreón E, Zamarro J, Espinosa de Rueda M, García-Villalba B, Marín F, et al: Recanalization and mortality rates of thrombectomy with stent-retrievers in octogenarian patients with acute ischemic stroke. Cardiovasc Intervent Radiol 2015;38:288-294. 
7 Goyal M, Menon BK, van Zwam WH, Dippel DW, Mitchell PJ, Demchuk AM, et al: Endovascular thrombectomy after large-vessel ischaemic stroke: a meta-analysis of individual patient data from five randomised trials. Lancet 2016;387:1723-1731.

8 Saver JL, Goyal M, Bonafe A, Diener HC, Levy EI, Pereira VM, et al: Stent-retriever thrombectomy after intravenous t-PA vs t-PA alone in stroke. N Engl J Med 2015;372:2285-2295.

9 Jovin TG, Chamorro A, Cobo E, de Miquel MA, Molina CA, Rovira A, et al: Thrombectomy within $8 \mathrm{~h}$ after symptom onset in ischemic stroke. N Engl J Med 2015;372:2296-2306.

10 Palesch YY, Yeatts SD, Tomsick TA, Foster LD, Demchuk AM, Khatri P, et al: Twelve-month clinical and qualityof-life outcomes in the Interventional Management of Stroke III Trial. Stroke 2015;46:1321-1327.

11 Berkhemer OA, Fransen PS, Beumer D, van den Berg LA, Lingsma HF, Yoo AJ, et al: A randomized trial of intraarterial treatment for acute ischemic stroke. N Engl J Med 2015;372:11-20.

12 Goyal M, Demchuk AM, Menon BK, Eesa M, Rempel JL, Thornton J, et al: Randomized assessment of rapid endovascular treatment of ischemic stroke. N Engl J Med 2015;372:1019-1030.

13 Campbell BC, Mitchell PJ, Kleinig TJ, Dewey HM, Churilov L, Yassi N, et al: Endovascular therapy for ischemic stroke with perfusion-imaging selection. N Engl J Med 2015;372:1009-1018.

14 Campbell BC, Hill MD, Rubiera M, Menon BK, Demchuk A, Donnan GA, et al: Safety and efficacy of solitaire stent thrombectomy: individual patient data meta-analysis of randomized trials. Stroke 2016;47:798-806.

15 Chandra RV, Leslie-Mazwi TM, Oh DC, Chaudhry ZA, Mehta BP, Rost NS, et al: Elderly patients are at higher risk for poor outcomes after intra-arterial therapy. Stroke 2012;43:2356-2361.

16 Mueller-Kronast NH, Zaidat O0, Froehler MT, Jahan R, Aziz-Sultan MA, Klucznik RP, et al: Systematic evaluation of patients treated with neurothrombectomy devices for acute ischemic stroke: primary results of the STRATIS registry. Stroke 2017;48:2760-2768.

17 Winovich DT, Longstreth WT Jr, Arnold AM, Varadhan R, Zeki Al Hazzouri A, Cushman M, et al: Factors associated with ischemic stroke survival and recovery in older adults. Stroke 2017;48:1818-1826.

18 Danière F, Lobotesis K, Machi P, Eker O, Mourand I, Riquelme C, et al: Patient selection for stroke endovascular therapy - DWI-ASPECTS thresholds should vary among age groups: insights from the RECOST study. AJNR Am J Neuroradiol 2015;36:32-39.

19 Nogueira RG, Jadhav AP, Haussen DC, Bonafe A, Budzik RF, Bhuva P, et al: Thrombectomy 6 to 24 hours after stroke with a mismatch between deficit and infarct. N Engl J Med 2018;378:11-21.

20 Millán M, Remollo S, Quesada H, Renú A, Tomasello A, Minhas P, et al: Vessel patency at 24 hours and its relationship with clinical outcomes and infarct volume in REVASCAT trial (Randomized Trial of Revascularization with Solitaire FR Device versus Best Medical Therapy in the Treatment of Acute Stroke due to Anterior Circulation Large Vessel Occlusion Presenting within Eight Hours of Symptom Onset). Stroke 2017;48:983-989.

21 Son S, Kang DH, Hwang YH, Kim YS, Kim YW: Efficacy, safety, and clinical outcome of modern mechanical thrombectomy in elderly patients with acute ischemic stroke. Acta Neurochir (Wien) 2017, Epub ahead of print.

22 Broussalis E, Weymayr F, Hitzl W, Unterrainer AF, Trinka E, Killer M: Endovascular mechanical recanalization of acute ischaemic stroke in octogenarians. Eur Radiol 2016;26:1742-1750.

23 Azkune Calle I, Bocos Portillo J, Anton-Ladislao A, Gil Garcia A, Gonzalez Diaz E, Gomez-Beldarrain M, et al: Clinical outcome of mechanical thrombectomy for stroke in the elderly. J Stroke Cerebrovasc Dis 2017;26: 582-588.

24 Duffis EJ, He W, Prestigiacomo CJ, Gandhi CD: Endovascular treatment for acute ischemic stroke in octogenarians compared with younger patients: a meta-analysis. Int J Stroke 2014;9:308-312.

25 Lima A, Haussen DC, Rebello LC, Dehkharghani S, Grossberg J, Grigoryan M, et al: Endovascular therapy for large vessel stroke in the elderly: hope in the new stroke era. Cerebrovasc Dis 2016;42:421-427.

26 To CY, Rajamand S, Mehra R, Falatko S, Badr Y, Richards B, et al: Outcome of mechanical thrombectomy in the very elderly for the treatment of acute ischemic stroke: the real world experience. Acta Radiol Open 2015;4: 2058460115599423.

27 Hwang K, Hwang G, Kwon OK, Kim CH, Ban SP, Han MK, et al: Endovascular treatment for acute ischemic stroke patients over 80 years of age. J Cerebrovasc Endovasc Neurosurg 2015;17:173-179.

28 Epstein SE, Lassance-Soares RM, Faber JE, Burnett MS: Effects of aging on the collateral circulation, and therapeutic implications. Circulation 2012;125:3211-3219.

29 Qureshi AI, Suri MF, Georgiadis AL, Vazquez G, Janjua NA: Intra-arterial recanalization techniques for patients 80 years or older with acute ischemic stroke: pooled analysis from 4 prospective studies. AJNR Am J Neuroradiol 2009;30:1184-1189.

30 Steen Carlsson K, Andsberg G, Petersson J, Norrving B: Long-term cost-effectiveness of thrombectomy for acute ischaemic stroke in real life: an analysis based on data from the Swedish Stroke Register (Riksstroke). Int J Stroke 2017;12:802-814.

31 Mangla S, O'Connell K, Kumari D, Shahrzad M: Novel model of direct and indirect cost-benefit analysis of mechanical embolectomy over IV tPA for large vessel occlusions: a real-world dollar analysis based on improvements in mRS. J Neurointerv Surg 2016, Epub ahead of print. 